$\underline{\text { Original Article }}$

\title{
Prognostic Value of Protease Activated Receptor-1 in Children with Acute Lymphoblastic Leukemia
}

\author{
Adel A. Hagag ${ }^{1}$, Nahla A. Nosair², Fatma M.Ghaith² and Eman H. Elshenawy ${ }^{2}$ \\ ${ }^{1}$ Department of Pediatrics, Faculty of Medicine. Tanta University. Egypt \\ ${ }^{2}$ Department of Clinical Pathology, Faculty of Medicine. Tanta University. Egypt
}

Correspondence to: Adel A. Hagag, Department of Pediatrics, Faculty of Medicine. Tanta University. Egypt Competing interests: The authors have declared that no competing interests exist.

Published: April 7, 2014

Received: January 23, 2014

Accepted: March 11, 2014

Citation: Mediterr J Hematol Infect Dis 2014, 6(1): e2014029, DOI: 10.4084/MJHID.2014.029

This article is available from: http://www.mjhid.org/article/view/12810

This is an Open Access article distributed under the terms of the Creative Commons Attribution License (http://creativecommons.org/licenses/by/2.0), which permits unrestricted use, distribution, and reproduction in any medium, provided the original work is properly cited.

\begin{abstract}
Background: Acute Lymphoblastic leukemia (ALL) is a malignant disorder of lymphoid progenitor cells that proliferate and replace the normal hematopoietic cells of the bone marrow. Protease-activated receptors (PARs) comprise a family of trans-membrane G-protein coupled receptors. Protease-activated receptor 1 (PAR-1) is a typical member of this family of receptors that mediate cellular responses to thrombin and related proteases. PAR1 is expressed by a wide range of tumor cells and can promote tumor growth, invasion and metastasis. The aim of this work was to study the role of PAR-1 expression in newly diagnosed ALL patients.
\end{abstract}

Patients and methods: This study was conducted on 44 children with newly diagnosed ALL who were admitted to Hematology Unit, Pediatric department, Tanta University Hospital including 24 males and 20 females with their age ranged from 4-17 years and their mean age value of 9.06 \pm 3.26 . All patients were subjected to complete history taking, thorough clinical examination, bone marrow aspiration and flow cytometric analysis for detection of PAR-1 expression by malignant cells.

Results: PAR-1 was positive in 18 cases $(41 \%)$ and negative in 26 cases $(59 \%)$ of studied patients. This study showed no significant relation between PAR-1 expression and age, sex and most of the clinical data including hepatomegaly, splenomegaly and purpura while generalized lymphadenopathy was significantly higher in PAR-1 positive group. PAR-1 positive expression was associated with some bad prognostic laboratory parameters including higher hemoglobin, higher white blood cells, higher peripheral blood and bone marrow blast cells, higher serum LDH and lower platelets count. No significant association was detected between PAR-1 expression and immunophenotyping. There were significantly higher remission rates in PAR-1 negative group and significantly higher relapse and death rates in PAR-1 positive group.

Conclusion: From this study, it could be concluded that PAR-1 expression on ALL cells represents an important adverse prognostic factor.

Recommendations: PAR-1 expression should be routinely investigated for better prognostic assessment of ALL patients at diagnosis and should be taken in consideration in designing future therapeutic strategies based on patients- specific risk factors. 
Introduction. Acute lymphoblastic leukemia (ALL) is a malignant disorder of lymphoid progenitor cells that proliferate and replace the normal hematopoietic cells of the bone marrow resulting in a marked decrease in normal blood cell production ${ }^{1}$ and is the most common childhood malignancy, representing nearly one third of all pediatric cancers; the annual incidence is approximately 9-10 cases per 100.000 populations in childhood. ${ }^{2}$ Typically, ALL develops quite quickly (acutely) and rapidly becomes worse unless treated ${ }^{(3)}$ as it spreads into the blood stream and other vital organs quickly. ${ }^{4}$

Many studies over the past 20 years looked at the role of various cellular phenotype assessed at initial diagnosis in predicting therapy response. The associations generally have been strong and are clearly predictive when coupled with several factors such as age, sex, initial hemoglobin level, and total leucocytic and platelets counts. ${ }^{5}$

Protease-activated receptors, (PARs) comprise a family of trans-membrane G- protein coupled receptors that are uniquely activated by proteolytic cleavage of their extracellular portion. This cleavage "unmasks" a new N-terminus, which serves as a "tethered" ligand that binds to the second extracellular domain of the protein, resulting in a variety of cellular responses. ${ }^{6}$ Protease-activated receptor 1 (PAR-1) is a typical member of this family of receptors that mediate cellular responses to thrombin and related proteases. ${ }^{7}$

Physiologically, PAR-1 is expressed by different tissues including vascular cells, neurons, fibroblasts, epithelial cells and others. ${ }^{8}$ PAR-1 has been shown to be overexpressed in various human cancers including breast, melanoma, colon, prostate, ovarian, esophagus and others ${ }^{9}$ and has been associated with several protumoral responses including primary growth, aggressive behavior, invasion, metastasis and angiogenesis. ${ }^{10,11}$

PAR-1 is significantly elevated in aggressive leukemias including blast phase of CML and AML subtypes M4/M5, in contrast to chronic phase in CML and CLL. Therefore, this protein plays an important biological role in aggressive leukemias and might offer additional strategies for the development of new therapies. ${ }^{12}$

Subjects and Methods. This study was done after approval from Ethical Committee of research Center of Tanta University Hospital and written consent from parents of included children in this research and was carried out on 44 children with newly diagnosed ALL who were admitted to Hematology Unit, Pediatric department, Tanta University Hospital including 24 males and 20 females with their age ranged from 4-17 years and their mean age value of 9.06 \pm 3.26 . ALL was diagnosed according to clinical presentation, morphological, cytochemical smears together with immunophenotyping and was based on the presence of $\geq 20 \%$ blast cells in BM according to WHO proposal and MPO negative staining and immunophenotyping results consistent with ALL. ${ }^{13}$ Patients were followed up for 24 months for clinical outcome and fate of the disease.

ALL patients were subjected to the following:

1. Complete history taking

2. Thorough clinical examination: with an especial account on pallor, purpura, hepatomegaly, splenomegaly and lymphadenopathy.

3. Laboratory investigations.

Specimen collection and handling: Four $\mathrm{ml}$ of venous blood were collected using sterile needles through gentle venipuncture after sterilization of the puncture site by alcohol, and collected samples were divided into; one ml was delivered on 20 uL EDTA solution for complete blood count including differential white blood cells count which was done on Leishman stained peripheral blood smear with evaluation using ERMA PCE-210 N cell -counter ${ }^{14}$ and the rest of blood was put in a plain tube and serum was separated for estimation of LDH.

Bone marrow aspiration: Bone marrow aspiration was performed under complete aseptic technique. Smears of direct bone marrow aspirate were prepared, stained with Lieshman stain for morphologic study and cytochemical stains with Sudan black and Myeloperoxidase and Immunophenotyping using the following panel of fluorescein isothiocyanate / phycoerythrin conjugated monoclonal antibodies:

Lymphoid cell markers.

T-cell markers (CD2, CD3, CD5, CD7).

B-cell markers (CD10, CD19, CD20, CD22).

Myeloid cell markers (CD13, CD33) ${ }^{(15)}$.

Immunophenotyping for evaluation of PAR-1: One $\mathrm{ml}$ of bone marrow or peripheral blood samples (with more than $20 \%$ blast cells) were withdrawn on EDTA tubes. Evaluation of PAR-1 was done using Becton Dickinson FAC Scan flow cytometer (BD FACS). ${ }^{16}$ Monoclonal antibodies PAR-1/APC, anti-human reagent for identification of cell expression PAR-1 labeled with fluorescein, commercially available by R\&D Systems; FAB3855A. The percentage of blast cells positive for PAR-1 was determined as a percentage from the gated blast cells populations. The negative control was set at $2 \%$. A case was defined as PAR-1 positive if $\geq 20 \%$ of the gated cells expressed PAR-1. ${ }^{17}$

Follow up of patients was done clinically and by blast cell count in the bone marrow (BM) on day 21 after induction chemotherapy which includes: Vincristine $1.5 \mathrm{mg} / \mathrm{kg} / \mathrm{m}^{2} /$ week IV (days $0,7,14,21$, 28 , 35), Doxorubicin $25 \mathrm{mg} / \mathrm{m}^{2} /$ week IV infusion (days 
$0,7,14,21,28,35)$, L-Asparginase $6000 \mathrm{u} / \mathrm{m}^{2} \mathrm{SC}$ on alternate days for 10 doses, and Prednisone $40 \mathrm{mg} / \mathrm{m}^{2} /$ day for 6 weeks orally. Bone marrow aspiration was done on day 21. In non-responding cases, we add Etopsoide $100 \mathrm{mg} / \mathrm{m}^{2} /$ dose IV (days 22, 25, 29), Cyclophosphamide $750 \mathrm{mg} / \mathrm{m}^{2} /$ dose IV infusion (days 22, 25, 29), Aracytin $100 / \mathrm{m}^{2} /$ dose IV (days 22, 25, 29), and methotrexate $5 \mathrm{~g} / \mathrm{m}^{2}$ over 4 hours on day $28 .^{18}$

Definition of complete remission and relapse: Complete remission (CR) is defined as a cellularity of more than $20 \%$ with fewer than $5 \%$ blasts in bone marrow after induction chemotherapy. ${ }^{19}$ Relapse is defined by the appearance of one of the following: (1) more than $50 \%$ lymphoblasts in a single BM aspirate; (2) more than $25 \%$ lymphoblasts in BM and $2 \%$ or more circulating lymphoblasts; (3) progressive repopulation of lymphoblasts in excess of $5 \%$ culminating in more than $25 \%$ on two or more BM samples separated by 1 week or more; (4) leukemic cell infiltration in extra medullary organs as gonads; (5) lymphoblasts in CSF with cell count greater than 5 $\mathrm{WBCs} / \mathrm{mm}^{3} .^{20}$

Statistical analysis: Statistical presentation and analysis of the present study was conducted, using the mean, the standard error, student $t$ - test and Chi- square tests by SPSS V17.

\section{Results.}

Table 1. Clinical characteristics of studied ALL patients.

\begin{tabular}{|l|c|c|c|c|}
\hline & $\begin{array}{c}\text { PAR-1 } \\
\text { positive } \\
(\text { No=18) }\end{array}$ & $\begin{array}{c}\text { PAR-1 } \\
\text { negative } \\
(\text { No=26) }\end{array}$ & \multicolumn{2}{|c|}{ T value P value } \\
\hline $\begin{array}{l}\text { Age } \\
\text { Range } \\
\text { Mean } \pm \text { SD }\end{array}$ & $\begin{array}{c}5-17 \\
8.75 \pm 3.56\end{array}$ & $\begin{array}{c}4-15 \\
9.17 \pm 3.28\end{array}$ & 0.245 & 0.24 \\
\hline $\begin{array}{l}\text { Sex } \\
\text { Males } \\
\text { Females }\end{array}$ & 10 & 14 & & \\
\hline Pallor & 8 & 12 & 0.023 & 0.880 \\
\hline Purpura & 12 & 18 & 0.052 & 0.819 \\
\hline Hepatomegaly & 14 & 21 & 3.772 & 0.052 \\
\hline Splenomegaly & 16 & 23 & 1.250 & 0.263 \\
\hline Lymphadenopathy & 16 & 22 & 0.052 & 0.819 \\
\hline
\end{tabular}

Table 1 shows no significant differences between PAR-1 positive and PAR-1 negative patients regarding age, sex, pallor, purpura, hepatomegaly and splenomegaly while there was statistically significant difference between PAR-1 positive and PAR-1 negative patients regarding lymphadenopathy with a higher incidence of lymphadenopathy in PAR-1 positive patients.

Table 2 shows statistically significant differences between PAR-1 positive and PAR-1 negative patients
Table 2. Laboratory data of studied ALL patients.

\begin{tabular}{|c|c|c|c|c|}
\hline & $\begin{array}{c}\text { PAR-1 } \\
\text { positive } \\
(\text { No }=18)\end{array}$ & $\begin{array}{c}\text { PAR-1 } \\
\text { negative } \\
(\mathrm{No}=26)\end{array}$ & \multicolumn{2}{|c|}{$\mathrm{T}$ value $\mathrm{P}$ value } \\
\hline $\begin{array}{l}\text { Hemoglobin } \\
\text { (gm/dl) } \\
\text { Range } \\
\text { Mean } \pm \text { SD }\end{array}$ & $\begin{array}{c}8.2-11.7 \\
9.32 \pm 1.67\end{array}$ & $\begin{array}{c}5.8-9.2 \\
6.13 \pm 1.06\end{array}$ & 2.83 & $0.01 *$ \\
\hline $\begin{array}{l}\text { WBCs } \\
\left(\times 10^{3} / \mathrm{mm}^{3}\right) \\
\text { Range } \\
\text { Mean } \pm \text { SD }\end{array}$ & $\begin{array}{c}25-180 \\
124.90 \pm 48.21\end{array}$ & $\begin{array}{c}11-150 \\
47.43 \pm 40.78\end{array}$ & 4.74 & $\begin{array}{l}<0.01 \\
*\end{array}$ \\
\hline $\begin{array}{l}\text { Platelets } \\
\left(\times 10^{3} / \mathrm{mm}^{3}\right) \\
\text { Range } \\
\text { Mean } \pm \text { SD }\end{array}$ & $\begin{array}{c}10-70 \\
34.83 \pm 22.21\end{array}$ & $\begin{array}{c}13-80 \\
53.21 \pm 25.06\end{array}$ & 2.06 & $0.04 *$ \\
\hline $\begin{array}{l}\text { PB blasts (\%) } \\
\text { Range } \\
\text { Mean } \pm \text { SD }\end{array}$ & $\begin{array}{c}39-80 \\
61.71 \pm 13.10 \\
\end{array}$ & $\begin{array}{c}8-60 \\
25.03 \pm 17.84 \\
\end{array}$ & 6.09 & $\begin{array}{l}<0.01 \\
* \\
\end{array}$ \\
\hline $\begin{array}{l}\text { BM blasts (\%) } \\
\text { Range } \\
\text { Mean } \pm \text { SD }\end{array}$ & $\begin{array}{c}38-94 \\
74.08 \pm 16.24\end{array}$ & $\begin{array}{c}25-87 \\
43.57 \pm 21.18\end{array}$ & 4.22 & $\begin{array}{l}<0.01 \\
*\end{array}$ \\
\hline $\begin{array}{l}\text { LDH (U/L) } \\
\text { Range } \\
\text { Mean } \pm \text { SD }\end{array}$ & $\begin{array}{c}570-2100 \\
937.58 \pm 493.6 \\
\end{array}$ & $\begin{array}{c}460-620 \\
527.64 \pm 52.2 \\
\end{array}$ & 2.87 & $0.02 *$ \\
\hline $\begin{array}{l}\text { Immuno- } \\
\text { phenotyping } \\
\text { B- cell ALL } \\
\text { T- cell ALL }\end{array}$ & $\begin{array}{c}15 \\
3 \\
\end{array}$ & $\begin{array}{c}21 \\
5\end{array}$ & 0.978 & 0.322 \\
\hline
\end{tabular}

* Significant

regarding hemoglobin and LDH levels, total white blood cells and platelets counts, peripheral blood and BM blast cells percentage with higher hemoglobin and LDH levels, total white blood cells count, peripheral blood and BM blast cells percentage in PAR-1 positive patients while there were significantly lower platelets counts in PAR-1 positive than PAR-1 negative patients and no significant difference between PAR-1 positive and PAR-1 negative patients regarding immunophenotyping.

Table 3 shows statistically significant difference

Table 3. Prognostic value of PAR-1 positive expression in ALL patients.

\begin{tabular}{|c|c|c|c|c|}
\hline \multirow{2}{*}{\multicolumn{2}{|c|}{ PAR-1 expression }} & \multicolumn{3}{|c|}{ Patients outcome ( $\mathrm{No}=44)$} \\
\hline & & \multirow{2}{*}{$\begin{array}{l}\text { Death } \\
1(2.2)\end{array}$} & \multirow{2}{*}{$\begin{array}{l}\text { Remission } \\
21(47.7)\end{array}$} & \multirow{2}{*}{$\begin{array}{l}\text { Relapse } \\
4 \text { (9) }\end{array}$} \\
\hline $\begin{array}{l}\text { PAR-1 } \\
\text { Negative } \\
(\mathrm{No}=26) \\
(59 \%)\end{array}$ & & & & \\
\hline $\begin{array}{l}\text { PAR-1 } \\
\text { Positive } \\
(\mathrm{No}=18) \\
(41 \%)\end{array}$ & & 7 (15.9) & $6(13.6)$ & 5 (11.3) \\
\hline $\begin{array}{l}\text { Total Number } \\
=44(100 \%)\end{array}$ & & $8(18.18)$ & 27 (61.3) & $9(20.45)$ \\
\hline \multirow{2}{*}{ Chi-square } & $X^{2}$ & \multicolumn{3}{|l|}{28.015} \\
\hline & p-value & \multicolumn{3}{|l|}{$<0.001^{*}$} \\
\hline
\end{tabular}

*Highly significant $(\mathrm{p}<0.01)$ 

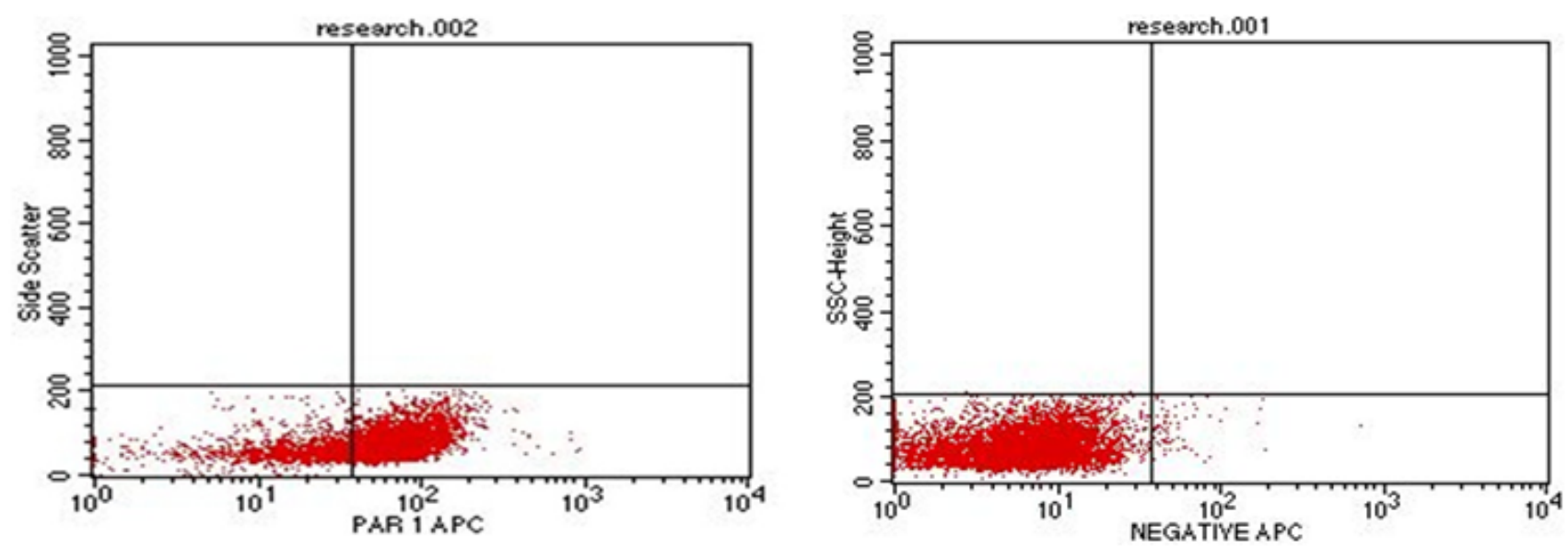

Figure 1. Flow cytometric analysis showing positive case for PAR-1 with high expression (to the left) and negative control for PAR-1 (to the right)

Survival Functions

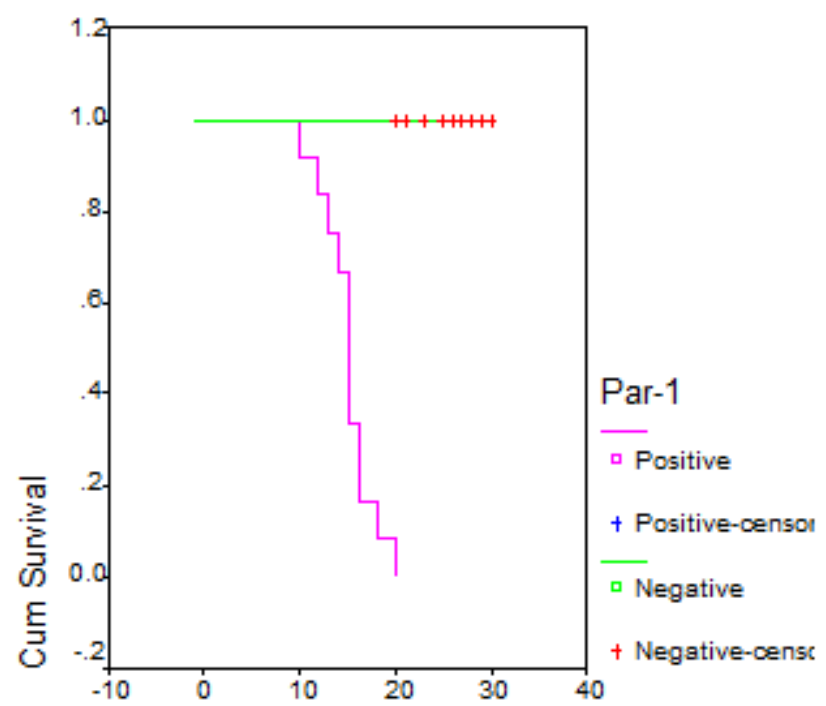

Time of follow up

\section{Log $R$ ank $=36.73 \quad$ P-value $=0.0000$ \\ Median $=15.00 \quad \mathrm{SE}=0.41$}

Survival Functions

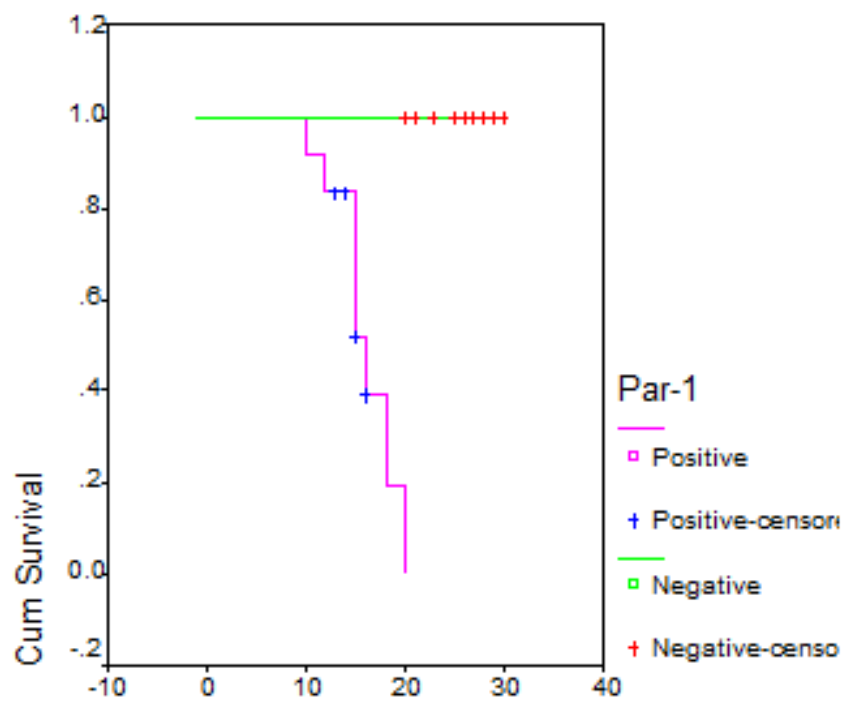

Time of follow up

$\begin{array}{ll}\text { Log Rank }=26.30 & \text { P-value }=0.0000 \\ \text { Median }=16.00 & \mathrm{SE}=1.48\end{array}$

Figure 2. Disease free survival curve (DFS) (to the left) and Overall survival curve (OAS) (to the right). There were statistically significant differences in DFS and OAS between PAR-1 positive and PAR-1 negative groups.

between PAR-1 positive and PAR-1 negative expression regarding relapse, death and remission rates with higher relapse and death and lower remission rates in PAR-1 positive group (Fig. 1 and 2).

Discussion. ALL is the most common childhood malignancy, representing nearly one third of all pediatric cancers. It has become a curable disease in over than $80 \%$ of patients with current treatments. However, the treatment of ALL results in significant morbidity and mortality. The use of risk-adapted treatment protocols has improved cure rates while limiting the toxicity of therapy. ${ }^{21}$ PAR-1 plays an important biological role in aggressive leukemias and might offer additional strategies for the development of new therapies. ${ }^{12}$

The present research was done to evaluate the prognostic value of PAR-1 expression in 44 children with newly diagnosed ALL who were admitted to Hematology Unit, Pediatric department, Tanta University Hospital including 24 males and 20 females with their age ranged from 4-17 years and their mean age value of 9.06 \pm 3.26 and they included 18 PAR-1 positive patients and 26 PAR-1 negative patients.

There were no significant differences between PAR-1 positive and PAR-1 negative patients regarding 
age, sex, pallor, purpura, hepatomegaly and splenomegaly while there was statistically significant difference between PAR-1 positive and PAR-1 negative patients regarding lymphadenopathy with a higher incidence of lymphadenopathy in PAR-1 positive patients. These findings were consistent with Mook et al., $2004^{22}$ who found the same results.

In the present series, there were normocytic normochromic anemia, leukocytosis and thrombocytopenia in studied leukemic patients. This was in agreement with Biswas et al, $2009^{23}$ who found the same results and explained this by direct result of the diffuse and heavy BM and peripheral blood infiltration due to uncontrolled proliferation of lymphoblasts.

In our study PAR-1 positive expression at diagnosis was significantly associated with bad clinical and laboratory prognostic factors including lymphadenopathy, higher hemoglobin levels, higher white blood cells, higher peripheral blood and bone marrow blast cells and higher serum LDH and lower platelets count. These findings were consistent with Boire et al., $2005^{24}$ and Salah et al., 2007 ${ }^{11}$ who demonstrated that positive PAR-1 expression was associated significantly with various clinicopathologic features and several pro-tumoral responses including primary growth, invasion, lymph node metastasis and depth of tumor invasion and Veiga et al., $2011^{12}$ who found significantly higher circulating peripheral blood and BM blasts in PAR-1 positive ALL compared to PAR-1 negative cases.

In this study, $81 \%$ of patients were B-ALL, and $19 \%$ were T-ALL. This was in agreement with Ahmed and Hassab $2008^{25}$ who found that $83.3 \%$ of patients were B-ALL and $14.6 \%$ were T-ALL. There were no significant statistical association could be observed between PAR-1 expression and immunophenotyping of ALL. This finding was in agreement with Veiga et al., 2011. ${ }^{12}$

In our study, there were statistically significant differences between PAR-1 positive and PAR-1 negative expression regarding relapse, death and remission rates with higher relapse and death and lower remission rates in PAR-1 positive group. This was in agreement with Veiga et al., $201{ }^{(12)}$ who stated that

\section{References:}

1. Whitlock JA, Maloney KW, Carroll WL, et al: Down syndrome childhood acute lymphoblastic leukemia has a unique spectrum of sentinel cytogenetic lesions that influences treatment outcome: A report from the Children's Oncology Group. Blood 2010; 19; 116 (7)1045-50.

2. Ribera JM, Oriol A, Sanz MA, et al. Acute lymphoblastic leukemia in adolescents and young adults. Hemtol Oncol Clin North Am 2009; 23(5): 1033-1042.

http://dx.doi.org/10.1016/j.hoc.2009.07.002

3. Pui CH, Robison LL and Look AT. Acute lymphoblastic leukemia. positive PAR-1 expression was significantly elevated in aggressive leukemias, including blast phase of CML, AML subtypes M4/M5 and B cell ALL in contrast with CML, in chronic phase, and CLL and was associated with poor treatment outcome, Depasquale and Thompson $2008^{26}$ who demonstrated that PAR-1 expression is a negative prognostic factor in melanomas and strongly correlates with tumor stage and Meis et al $2010^{27}$ who found decreased long-term survival in PAR-1 expressing patients with lung adenocarcinoma compared with PAR-1 negative patients .

It was found that PAR-1 can promote tumor growth, invasion and metastasis. ${ }^{24}$ In addition PAR-1 activation stimulates proliferation and decreases idarubicin induced cell death in vitro. ${ }^{28}$ The zinc-dependent matrix metalloprotease 1 (MMP-1), also known as interstitial collagenase, has been reported to promote tumor growth and invasion through activation of PAR-1, providing an important link between tumor-generated metalloproteases and PAR-1 expression (Boire et al., 2005). ${ }^{24}$

PAR-1 plays a primary role in the process of metastasis by stimulating the secretion of matrix metalloproteinase by virtue of their ability to degrade the extracellular matrix (ECM) barrier. However, MMPs are also capable of cleaving non-ECM molecules. The protease-activated receptors (PARs) are the latest MMP targets. The thrombin receptor PAR-1 has now been shown to be cleaved and activated on the tumor cell surface by stromal-derived MMP1. The resulting PAR1 activates intracellular $G$ proteins to turn on the migratory and invasive program in tumor cells. This MMP-PAR axis may represent a novel signaling pathway communicating between tumor and stromal cells during tumor progression. ${ }^{29}$

Conclusion. PAR-1 expression on ALL cells represents an important adverse prognostic factor and therefore its expression should be routinely investigated for better prognostic assessment of ALL patients at diagnosis and should be taken in consideration in designing future therapeutic strategies based on patient- specific risk factors.
Lancet 2008; 371:1030-1043. http://dx.doi.org/10.1016/S01406736(08)60457-2

4. Marshall G.M, Haber M, Kwan E et al. Importance of minimal residual disease testing during the second year of therapy for children with acute lymphoblastic leukemia. J Clin Oncol 2006; 21 : 704-709. http://dx.doi.org/10.1200/JCO.2003.10.080

5. Vaskova M, Mejstrikova E, Kalina T, et al. Transfer of genomics information to flow cytometry: expression of CD27 and CD44 discriminates subtypes of acute lymphoblastic leukemia. Leukemia 2005; 19:876-878. http://dx.doi.org/10.1038/sj.leu.2403706 
6. Coughlin SR. Protease-activated receptors in hemostasis, thrombosis and vascular biology. J Thromb Haemost 2005; 3: 1800 -1814. http://dx.doi.org/10.1111/j.1538-7836.2005.01377.x

7. Zhang C, Srinivasan Y, Arlow DH, et al. High-resolution crystal structure of human protease-activated receptor 1. Nature 2012; 492(7429):387-92. http://dx.doi.org/10.1038/nature11701

8. Vergnolle N, Wallace JL, Bunnett NW, et al. Protease-activated receptors in inflammation, neuronal signaling and pain. Trends Pharmacol Sci 2001; 22:146-152. http://dx.doi.org/10.1016/S01656147(00)01634-5

9. Ribeiro FS, Simão TA, Amoedo ND, et al. Evidence for increased expression of tissue factor and protease-activated receptor-1 in human esophageal cancer. Oncol Rep 2009; 21: 1599-1604.

10. Yin YJ, Salah Z, Maoz M, et al. Oncogenic transformation induces tumor angiogenesis: a role for PAR-1 activation. FASEB J 2003; 17: 163-174. http://dx.doi.org/10.1096/fj.02-0316com

11. Salah Z, Maoz M, Pokroy E, et al. Protease-activated receptor-1, a survival factor eliciting tumor progression. Mol Cancer Res 2007; 5: 229-240. http://dx.doi.org/10.1158/1541-7786.MCR-06-0261

12. Veiga S B, Tatiana C Carneiro-Lobo, Cláudia J B P Coelho, et al. Increased expression of protease-activated receptor 1 (PAR-1) in human leukemias. Blood Cells Molecules and Diseases. 2011; 46(3):230-4. http://dx.doi.org/10.1016/j.bcmd.2010.12.005

13. Harris N, Jaffe E, Diebold J, et al .The World Health Organization Classification of neoplasms of the hematopoietic and lymphoid tissues. J Clin Oncol 2000; 12:3835-3849.

14. Monica C. Strategy of blood safety in Africa region. In: Tito A and Lewis SM (eds). District laboratory practice in tropical countries, 2nd edition. Cambridge low price Egyptian edition 2005; chapter 4, P. 268-378.

15. Catovsky D and Hoffbrand AV. Acute myeloid leukaemia. In: A.V. Hoffbrand and S.M. Lewis (eds) Postgraduate Haematology, 5th edition, Oxford, UK: Reed Educational and Professional Publishing Ltd. 2005; 509-524.

16. Perfetto SP, Chattopadhyay PK, Lamoreaux L et al. Amine reactive dyes: an effective tool to discriminate live and dead cells in polychromatic flow cytometry. J Immunol Methods 2006; 313(12): 199-208. http://dx.doi.org/10.1016/j.jim.2006.04.007

17. Borowitz MJ, Westra W and Cooley L. Pathology and laboratory medicine. In: Adelof MD, Armitage JO and Neiderhuber JE. (eds).Clinical Oncology 3rd ed. Elsevier Churchill Livingston. 2004; Ch. 17: 299-329.

18. Marshall A Lichtman, Ernest Beulter, Uri Seligsonn, et al (eds). Acute lymphoplastic leukemia: Overview. In: William textbook of
Hematology. 17th edition, New York: McGraw-Hill Companies, Inc. 2007; chapter 91: 1141-53.

19. David G Tubergen and Archie Bleyer. The Leukemias. In: Behrman RE, Kliegman RM, Jenson HB (eds). Nelson Textbook of Pediatrics, 18th edition, Philadelphia, USA: Saunders an imprint of Elsevier Inc. 2007: 2116-2112.

20. Lanzkowsky PH: Leukemias. In: Lanzkowsky Philip (editor), Manual of Pediatric Hematology and Oncology. 4th ed. Churchil livingstane. Nek, London, Madrid 2011; 17: 518- 566.

21. Hagag AA, Abdel-Lateef AE, Aly R. Prognostic value of plasma levels of thrombomodulin and von Willebrand factor in Egyptian children with acute lymphoblastic leukemia. J Oncol Pharm Pract 2013 Nov 15. [Epub ahead of print PMID: 24243921.

22. Mook OR, Frederiks WM and Van Noorden CJ. The role of gelatinases in colorectal cancer progression and metastasis. Biochim Biophys Acta 2004; 1705:69-89.

23. Biswas S, Chakrabarti S, Chakraborty J, et al: Childhood Acute Leukemia in West Bengal, India with an Emphasis on Uncommon Clinical Features. Asian Pacific J Cancer Prev 2009; (10): 903-906.

24. Boire A, Covic L, Agarwal A, et al. PAR1 is a matrix metalloprotease-1 receptor that promotes invasion and tumorigenesis of breast cancer cells. Cell 2005; 120: 303-313. http://dx.doi.org/10.1016/j.cell.2004.12.018

25. Ahmed MS and Hassab HM. Study of soluble CD44 and its expression by mononuclear cells in children with acute lymphoblastic leukemia: its relation to prognostic factors. Egypt J Immunol 2008; 15(2): 101-111.

26. I. Depasquale and WD Thompson, Prognosis in human melanoma: PAR-1 expression is superior to other coagulation components and VEGF. Histopathology 2008; 52:500-509. http://dx.doi.org/10.1111/j.1365-2559.2008.02978.x

27. De Meis E, Azambuja D, Ayres-Silva JP, et al. Increased expression of tissue factor and protease activated receptor -1 does not correlate with thrombosis in human lung adenocarcinoma. Braz J of Med Biol Res 2010; 43(4):403-8. http://dx.doi.org/10.1590/S0100-879X2010007500017

28. H. Schiller, T. Bartscht, A. Arlt, et al. Thrombin as a survival factor for cancer cells: thrombin activation in malignant effusions in vivo and inhibition of idarubicin-induced cell death in vitro, Int. J. Clin Pharmacol. Ther. 40 (2002) 329-335. http://dx.doi.org/10.5414/CPP40329

29. Overall CM and Lopez-Otin C. Matrix metalloproteinase target protease-activated receptors on the tumor cell surface. Nat Rev Cancer 2002; 2: 657-672. http://dx.doi.org/10.1038/nrc884 